\title{
Sequence variants of interleukin $6(I L-6)$ are significantly associated with a decreased risk of late-onset Alzheimer's disease
}

Shih-Yuan Chen ${ }^{1}$, Ta-Fu Chen², Liang-Chuan Lai ${ }^{3}$, Jen-Hau Chen ${ }^{1,4}$, Yu Sun ${ }^{5}$, Li-Li Wen ${ }^{6}$, Ping-Keung Yip ${ }^{7}$, Yi-Min Chu ${ }^{8,9}$ and Yen-Ching Chen ${ }^{1,10,11^{*}}$

\begin{abstract}
Background: Interleukin 6 (IL-6) has been related to beta-amyloid aggregation and the appearance of hyperphosphorylated tau in Alzheimer's disease (AD) brain. However, previous studies relating IL-6 genetic polymorphisms to $A D$ included few and unrepresentative single nucleotide polymorphisms (SNPs) and the results were inconsistent.

Methods: This is a case-control study. A total of 266 patients with $A D$, aged $\geqq 65$, were recruited from three hospitals in Taiwan (2007-2010). Controls $(n=444)$ were recruited from routine health checkups and volunteers of the hospital during the same period of time. Three common IL-6 haplotype-tagging SNPs were selected to assess the association between IL-6 polymorphisms and the risk of late-onset AD (LOAD).

Results: Variant carriers of IL-6 rs1800796 and rs1524107 were significantly associated with a reduced risk of LOAD $[(G G+G C$ vs. $C C)$ : adjusted odds ratio $(A O R)=0.64$ and $(C C+C T$ vs. $T): A O R=0.60$, respectively]. Haplotype CAT was associated with a decreased risk of LOAD ( 0 and 1 copy vs. 2 copies: $A O R=0.65,95 \% \mathrm{Cl}=0.44-0.95$ ). These associations remained significant in ApoE e4 non-carriers only. Hypertension significantly modified the association between rs2069837 polymorphisms and the risk of LOAD ( $p_{\text {interaction }}=0.03$ ).

Conclusions: $I L-6$ polymorphisms are associated with reduced risk of LOAD, especially in ApoE e4 non-carriers. This study identified genetic markers for predicting LOAD in ApoE e4 non-carriers.
\end{abstract}

Keywords: IL-6, SNP, Haplotype, Alzheimer?'?s disease, Inflammation

\section{Background}

Dementia is a neurodegenerative disease characterized by decline or loss in cognitive function. Alzheimer's disease (AD) is the most common cause of dementia. In the United States in 2006, AD was the fifth leading cause of death in the elderly (age 65 or older) [1]. In Taiwan, the prevalence of dementia is around $1.7-4.3 \%$ among the elderly [2] and the number of dementia patients keeps increasing. Therefore, dementia has become an important health issue in aging populations.

Interleukin-6 (IL-6), an inflammatory cytokine, plays an important role in the development and differentiation

\footnotetext{
* Correspondence: karenchen@ntu.edu.tw

'Institute of Epidemiology and Preventive Medicine, College of Public Health, National Taiwan University, Taipei, Taiwan

Full list of author information is available at the end of the article
}

of neurons in both peripheral and central nervous system [3]. IL-6 promotes the activation of microglia [4] and then induces the synthesis of acute phase proteins [5] and phosphorylation of tau protein in neurons [6]. In AD brain, microglia and astrocytes are stimulated by IL-6 and are recruited to release proinflammatory cytokines and acute-phase proteins, such as C-reactive protein (CRP) [7]. Therefore, IL-6 plays a pivotal role in brain inflammation that maybe important in $\mathrm{AD}$ pathogenesis.

Previous studies relating $I L-6$ polymorphisms to AD risk have been inconsistent. A Caucasian study found that the CC genotype of $I L-6$ promoter SNP rs1800795 was significantly associated with an increased risk for $\mathrm{AD}$ [8]. However, this association has not been observed in other Caucasian studies [9-11]. In addition, the GG 
genotype of promoter SNP rs1800796 has been associated with a decreased risk for AD in two Chinese populations [12,13]. For the latter study [13], a significant association was observed only for Apolipoprotein $E$ (ApoE) e4 carriers. In contrast, no significant association was observed in a Japanese population [14]. Furthermore, the variant rs13447446 was very rare in a Korean study [minor allele frequency (MAF) $=0.006][15]$ and a Chinese study (MAF $=0$ ) [12] and thus no association analysis was performed. In summary, previous studies (see Table 1) have been inconsistent in relating $I L-6$ polymorphisms to $\mathrm{AD}$ risk. This may be attributable to different ethnic groups, SNPs selected, study period, or sample size.

IL-6 plays an important role in inflammation. Past studies relating $I L-6$ polymorphisms to AD risk have been limited to few and unrepresentative SNPs in $I L-6$. Some SNPs (e.g., rs13447446) even showed no variations in Asians. Therefore, this study used a systematic approach to select haplotype-tagging SNPs (htSNPs) in $I L-6$ to explore their association with $\mathrm{AD}$ risk. Because ApoE e4 status and some vascular risk factors [e.g., hypertension, hyperlipidemia, and type 2 diabetes mellitus (DM)] may affect the pathogenesis of dementia [16-18], this study further explored the effect of modification by these factors.

\section{Methods}

\section{Study population}

This was a case-control study. A total of 294 late-onset AD (LOAD) cases were recruited from the neurology clinics of three teaching hospitals in northern Taiwan from 2007 to 2010. Healthy controls $(\mathrm{n}=503)$ were recruited from elderly health checkup and volunteers of the hospital during the same period of time. All participants were Taiwanese aged 65 years or older. Participants with a history of depression, dementia subtypes other than AD, Parkinson's disease, hemorrhagic stroke, cerebral infarction, or organic brain tumors were excluded. After further exclusion of participants without blood samples, a total of 266 LOAD and 444 controls were included for data analyses. The study protocol has been approved by the Institutional Review Boards of National Taiwan University Hospital, En Chu Kong Hospital, and Cardinal Tien's Hospital. Written informed consent was obtained from each study participant. The consent from the legal guardian/next of kin was obtained when patients had serious cognitive impairment. A self-reported questionnaire was administered to collect information on demography, comorbidity (e.g., hypertension, hyperlipidemia, and type 2 DM), and lifestyle.

Table 1 Previous studies relating IL-6 polymorphisms to AD risk

\begin{tabular}{|c|c|c|c|c|}
\hline Reference & $\begin{array}{l}\text { Population } \\
\text { (AD:control) }\end{array}$ & $\begin{array}{l}\text { SNP (w.t./variant) } \\
\text { Haplotype (SNP) }\end{array}$ & Results & Limitations \\
\hline $\begin{array}{l}\text { Arosio et al. } \\
\text { Neurobiol. Aging 2004, } \\
\text { 25:1009-15 [9] }\end{array}$ & $\begin{array}{l}\text { Italian } \\
(65: 65)\end{array}$ & rs1800795 (G/C) & No significant association & $\begin{array}{l}\diamond \text { Italian only } \\
\diamond \text { One SNP only } \\
\diamond \text { Small sample size }\end{array}$ \\
\hline $\begin{array}{l}\text { Licastro et al. } \\
\text { Neurobiol. Aging } \\
\text { 2003, 24:921-26 [8] }\end{array}$ & $\begin{array}{l}\text { Italian } \\
\text { (332:393) }\end{array}$ & rs1800795 (G/C) & $\begin{array}{l}\text { rs1800795: } \\
\text { CC vs. GG: } \mathrm{OR}=1.62,95 \% \mathrm{Cl}= \\
\text { 1.20-2.17 }\end{array}$ & $\begin{array}{l}\diamond \mid \text { talian only } \\
\diamond \text { One SNP only }\end{array}$ \\
\hline $\begin{array}{l}\text { Depboylu et al. } \\
\text { Geriatr. Cogn. Disord } \\
\text { 2004, 17:170-73 [10] }\end{array}$ & $\begin{array}{l}\text { German } \\
(113: 108)\end{array}$ & rs1800795 (G/C) & No significant association & $\begin{array}{l}\diamond \text { German only } \\
\diamond \text { One SNP only }\end{array}$ \\
\hline $\begin{array}{l}\text { van Oijen et al. } \\
\text { Neurosci. Lett. } \\
\text { 2006, 402:113-17 [11] }\end{array}$ & $\begin{array}{l}\text { Netherlander } \\
(483: 5636)\end{array}$ & rs1800795 (G/C) & No significant association & $\begin{array}{l}\diamond \text { Netherlanders only } \\
\diamond \text { One SNP only }\end{array}$ \\
\hline $\begin{array}{l}\text { He et al. } \\
\text { Neurol. Sci. } \\
\text { 2010, 31:165-8 [12] }\end{array}$ & $\begin{array}{l}\text { Chinese } \\
(318: 324)\end{array}$ & $\frac{\mathrm{rs} 1800796}{\mathrm{rs} 13447446}(\mathrm{C} / \mathrm{G})$ & $\begin{array}{l}\text { rs 1800796: } \\
\text { GG vs. CC: } \mathrm{OR}=0.42,95 \% \mathrm{Cl}= \\
0.20-0.89\end{array}$ & $\begin{array}{l}\diamond \text { Chinese only } \\
\diamond \text { Not applicable for rs } 13447446 \text { (No GC } \\
\text { or CC variants) }\end{array}$ \\
\hline $\begin{array}{l}\text { Wang et al. } \\
\text { Neurosci. Lett. } \\
\text { 2010, 482:260-3 [13] }\end{array}$ & $\begin{array}{l}\text { Chinese } \\
(341: 421)\end{array}$ & $\begin{array}{l}\frac{\text { rs1800796 }(C / G)}{\text { rs7802308 }(A / T)} \\
\text { haplotype rs1800796/ } \\
\text { rs7802308 }\end{array}$ & $\begin{array}{l}\text { rs } 1800796 \text { (in ApoE e4 carrier): } \\
\text { 1) } \mathrm{CC} \text { vs. CG }+\mathrm{GG}: \mathrm{OR}=3.3 \text {, } \\
95 \% \mathrm{Cl}=1.64-6.67 \\
\text { 2) } \mathrm{A} \text { risk haplotype (CA) }(\mathrm{OR}= \\
\text { 2.24) } \\
\text { 3) } \mathrm{A} \text { protective haplotype (GA) } \\
(\mathrm{OR}=0.41)\end{array}$ & $\begin{array}{l}\diamond \text { Chinese only } \\
\text { \&ignificant only in ApoE e4-carrier } \\
\text { \&s7802308 is a rare SNP for analysis }\end{array}$ \\
\hline $\begin{array}{l}\text { Nishimura et al. } \\
\text { Neurosci. Lett. } \\
\text { 2004, 368:140-3 [14] }\end{array}$ & $\begin{array}{l}\text { Japanese } \\
(172: 163)\end{array}$ & $\underline{\mathrm{rs} 1800796}(\mathrm{C} / \mathrm{G})$ & No significant association & $\begin{array}{l}\diamond \text { Japanese only } \\
\diamond \text { One SNP only }\end{array}$ \\
\hline
\end{tabular}

a Words underlined indicates SNPs genotyped in our study.

Abbreviations: OR, odds ratio; AD, Alzheimer's disease; SNP, single nucleotide polymorphism; w.t., wild type. 


\section{Dementia evaluation}

At each hospital, potential dementia cases were diagnosed by a neurologist. The Mini-Mental State Examination (MMSE) was used to evaluate participants with cognitive impairment. The diagnosis of probable dementia was evaluated using Diagnostic and Statistical Manual of Mental Disorders (Fourth Edition) [19] criteria. Head magnetic resonance imaging and computed tomography were taken to exclude participants with organic lesions. National Institute of Neurological and Communicative Disorders and Stroke and the Alzheimer's Disease and Related Disorders Association (NINCDSADRDA) Alzheimer's Criteria [20] was used to diagnose probable AD. The cognitive function of controls was assessed by using Short Portable Mental Status Questionnaire [21] to exclude participants with possible dementia and other mental disorders.

\section{SNP selection and genotyping assay}

Genotype data of common (frequency $\geq 5 \%$ ) IL-6 SNPs were downloaded from the International HapMap Project (http://hapmap.ncbi.nlm.nih.gov) for Han Chinese in Beijing, China (CHB). Haploview (http://www.broadinstitute.org/haploview/haploview) was used to define haplotype block by using the modified Gabriel algorithm $[22,23]$. Two htSNPs were selected among four common SNPs using tagSNP program [24]. For comparison purpose, SNP rs1800796 was further included because it has been related to $\mathrm{AD}$ risk $[12,13]$.

Blood samples were collected in tubes containing sodium EDTA from each participant for genotyping. After centrifugation, genomic DNA was extracted from buffy coats using a QuickGene-Mini80 system (Fujifilm, Tokyo, Japan) and then stored in a $-80^{\circ} \mathrm{C}$ freezer. Genotypes of ApoE SNPs were determined using the assay developed by Chapman et al. [25]. Genotypes of $I L-6$ htSNPs were determined by Taqman Assay (Applied Biosystems Inc., CA, USA) with genotyping success rate greater than $95 \%$. Five percent of internal samples were selected and replicated for quality control, and the concordance rate was $100 \%$.

\section{Statistical analysis}

The distributions of demographic characteristics between cases and controls were compared using Student's $t$-test for normally distributed continuous variables and a chi-square test for categorical variables. The Hardy-Weinberg equilibrium (HWE) test was performed among controls to examine possible genotyping error and selection bias for each SNP. The ApoE diplotypes $(e 2 / e 2, e 2 / e 3, e 3 / e 3, e 2 / e 4, e 3 / e 4$, and $e 4 / e 4)$ were determined by ApoE112 (rs429358) and ApoE158 (rs7412) [26]. ApoE e4 carriers were defined as participants carrying $e 2 / e 4, e 3 / e 4$, or e4/e4 diplotypes; participants carrying other diplotypes $(e 2 / e 2, e 2 / e 3$, and $e 3 / e 3)$, were defined as $A p o E$ e 4 non-carriers. The expectation-maximization algorithm was utilized to estimate haplotype frequencies. Logistic regression models were performed to estimate SNP- and haplotype-specific odds ratios $(\mathrm{OR})$ and $95 \%$ confidence intervals $(\mathrm{CI})$ for LOAD adjusting for age, gender, education, and ApoE e4 status. Type I errors were controlled by using false discovery rate (FDR) [27].

A likelihood ratio test was used to evaluate how ApoE e4 status and vascular risk factors (e.g., type $2 \mathrm{DM}$, hypertension, and hyperlipidemia) modified the association between $I L-6$ polymorphisms and risk of LOAD. Stratified analyses were performed subsequently to assess the association between $I L-6$ polymorphisms and risk of LOAD by these vascular risk factors. SAS version 9.2 (SAS Institute, Cary, NC) was used for statistical analyses and all statistical tests were two-sided.

\section{Results}

\section{Characteristics of the study population}

This study included 266 incident LOAD cases and 444 controls. Compared with controls, LOAD cases were older (79.8 vs. 73.1 years old), included more females (64\% vs. $52 \%)$, had a lower education level ( $\leq 6$ years: $50 \%$ vs. $11 \%$ ), and included fewer with hypertension history ( $38 \%$ vs. $54 \%)$ or hyperlipidemia ( $18 \%$ vs. $30 \%)$, and more ApoE e4 carriers (39\% vs. $15 \%$, Table 2). The distributions of body mass index (BMI), cigarette smoking, alcohol consumption, and type $2 \mathrm{DM}$ were similar between LOAD cases and controls.

Table 2 Characteristics of the study population

\begin{tabular}{lll}
\hline Variables & AD & Control \\
& $\mathbf{N}=\mathbf{2 6 6}$ & $\mathbf{N}=\mathbf{4 4 4}$ \\
\hline Age (mean \pm SD) & $79.8 \pm 7.9^{*}$ & $73.1 \pm 7.1$ \\
Female (\%) & $170(64)^{*}$ & $233(52)$ \\
Education (\%) & & \\
$\quad \leqq 6$ years & $134(50)^{*}$ & $54(11)$ \\
$\quad 6-12$ years & $90(34)$ & $177(40)$ \\
$\quad>12$ years & $39(15)$ & $214(48)$ \\
BMl at age 40s, kg/m²(mean \pm SD) & $22.6 \pm 3.1$ & $22.4 \pm 2.8$ \\
Cigarette smoking (\%) & $62(23)$ & $77(17)$ \\
Alcohol consumption (\%) & $32(12)$ & $50(11)$ \\
Type 2 DM (\%) & $48(17)$ & $62(13)$ \\
Hypertension (\%) & $101(38)^{*}$ & $239(54)$ \\
Hyperlipidemia (\%) & $49(18)^{*}$ & $135(30)$ \\
ApoE e4 carriers (\%) & $104(39)^{*}$ & $66(15)$ \\
\hline
\end{tabular}

* $p$ value $<0.05$ was obtained by comparing $A D$ and controls. Abbreviations: $\mathrm{AD}$, Alzheimer's disease; $\mathrm{BMI}$, body mass index; $\mathrm{DM}$, diabetes mellitus; ApoE e4, apolipoprotein E e4. 


\section{ApoE SNPs}

Neither of the two ApoE SNPs (rs429358 and rs7412) was out of HWE (Table 3). AopE rs429358 (ApoE112) is a common SNP in this Chinese population (MAF $=0.08$ in controls) and in Caucasians (MAF $=0.15$, dbSNP dataset). In contrast, HapMap data showed that rs429358 is a rare variant in Chinese $(\mathrm{CHB}, \mathrm{MAF}=0)$ and Japanese $(\mathrm{JPN}, \mathrm{MAF}=0.01)$. The MAF is similar for ApoE rs7412 (ApoE158) across ethnic groups: Chinese (HapMap CHB: 0.11; controls of this study: 0.08), Caucasian (dbSNP: 0.08), and Japanese (HapMap: 0.05).

\section{IL-6 SNPs and AD risk}

Three IL-6 SNPs (rs1800796, rs2069837, and rs1524107) were genotyped. The MAFs of these SNPs among controls ranged from 0.19 to 0.27 , which were similar to the MAFs (0.20-0.25) of CHB genotype data from the International HapMap Project (Table 3). In contrast, MAF of these three IL-6 SNPs were lower in Japanese $(0.12,0.10$ and 0.18$)$ and in Caucasians $(0.04,0.08$, and 0.05 ) based on HapMap data. All IL-6 SNPs were in HWE among controls. For each SNP, the genotype frequencies were similar between cases and controls (data not shown).

Participants carrying one or two copies of variant SNP1 (rs1800796) or SNP3 (rs1524107) had a significantly decreased risk of LOAD [SNP1: adjusted OR $(\mathrm{AOR})=0.64,95 \% \mathrm{CI}=0.43-0.94 ; \mathrm{SNP} 3: \mathrm{AOR}=0.60$, 95\% CI $=0.41-0.89]$ compared with those carrying 0 copies. These results remained significant after controlling for FDR under dominant or additive model (Table 4). After stratification by $A p o E$ e4 status, SNP1 and SNP3 were significantly associated with decreased LOAD risk among ApoE e4 non-carriers (SNP1: AOR = $0.56,95 \% \mathrm{CI}=0.35-0.90$; SNP3: $\mathrm{AOR}=0.55,95 \% \mathrm{CI}=$ $0.35-0.88$, Table 4). These results remained statistically significant after controlling for FDR (Table 4). In contrast, results were not significant among $A p o E$ e4 carriers.

\section{IL-6 haplotypes and AD risk}

Three common (frequency $\geq 5 \%$ ) htSNPs spanning $I L-6$ formed one haplotype block, which was determined by the modified Gabriel et al. algorithm [22,23] (Figure 1). Three common haplotypes (CAT, GGC, and GAC) with a cumulative frequency of $99 \%$ in controls were identified in $I L-6$ (Table 5). Because HAP1 CAT is a "major" haplotype (haplotype frequency > 0.50), 2 copies of HAP1 were used as the reference group to be consistent with the reference groups used for HAP2 and HAP3, which are "minor" haplotypes (haplotype frequency < 0.50). Participants carrying 0 or 1 copies of major HAP1 CAT had a decreased risk of LOAD (AOR $=0.65,95 \%$ $\mathrm{CI}=0.44-0.95)$ compared to those carrying 2 copies of major HAP1.

\section{Effect modification by vascular risk factors}

Among the vascular risk factors explored in this study (e.g., hypertension, type 2 DM, and hyperlipidemia), hypertension was the only factor that significantly modified the association between $I L-6$ SNPs and risk of LOAD (SNP2: $p_{\text {interaction }}=0.03$ under dominant model, Table 6). Hypertension history significantly decreased the risk of LOAD $(\mathrm{AOR}=0.41,95 \% \mathrm{CI}=0.28-0.60$, Table 6). After stratification by hypertension status, hypertensive patients carrying variant SNP2 had a decreased risk of $\mathrm{LOAD}(\mathrm{AOR}=0.43,95 \% \mathrm{CI}=0.22$ 0.86, Table 6). Similar findings were observed for SNP1 and SNP3 (SNP1: AOR $=0.53,95 \% \mathrm{CI}=0.29-0.96$; SNP3: $A O R=0.53,95 \% \mathrm{CI}=0.29-0.97)$. After stratification by type 2 DM, non-DM patients carrying variant SNP1 and SNP3 were associated with a decreased LOAD risk $(A O R=0.54$ and 0.58 , Table 6). The associations above remained statistically significant after controlling for FDR.

For $I L-6$ haplotypes, vascular risk factors or ApoE e4 status did not significantly modify the association between IL-6 haplotypes and the risk of LOAD ( $\left.p_{\text {interaction }}>0.05\right)$. After stratification by hypertension history, hypertensive

Table 3 Characteristics of IL-6 haplotype-tagging SNPs and ApoE SNPs

\begin{tabular}{|c|c|c|c|c|c|c|c|c|c|c|c|c|}
\hline \multirow{4}{*}{ SNP name } & \multirow{4}{*}{ Nucleotide change } & \multirow{4}{*}{ Location } & \multirow{4}{*}{ rs no. } & \multirow{2}{*}{\multicolumn{3}{|c|}{$\begin{array}{c}\text { HapMap or dbSNP } \\
\text { MAF }\end{array}$}} & \multicolumn{6}{|c|}{ This study } \\
\hline & & & & & & & \multicolumn{3}{|c|}{ Controls } & \multicolumn{3}{|c|}{ Cases } \\
\hline & & & & \multirow[t]{2}{*}{ CEU } & \multirow[t]{2}{*}{ JPT } & \multirow[t]{2}{*}{$\mathrm{CHB}$} & \multirow[t]{2}{*}{ MAF } & \multicolumn{2}{|c|}{ HWE } & \multirow[t]{2}{*}{ MAF } & \multicolumn{2}{|c|}{ HWE } \\
\hline & & & & & & & & $\chi^{2}$ & $p$ & & $\chi^{2}$ & $p$ \\
\hline SNP1 & $C \rightarrow G$ & Promoter & rs1800796 & 0.04 & 0.14 & 0.23 & 0.26 & 0.98 & 0.32 & 0.22 & 0.36 & 0.55 \\
\hline SNP2 & $\mathrm{A} \rightarrow \mathrm{G}$ & Intron & rs2069837 & 0.08 & 0.10 & 0.17 & 0.19 & 2.59 & 0.11 & 0.16 & 0.04 & 0.84 \\
\hline SNP3 & $\mathrm{T} \rightarrow \mathrm{C}$ & Intron & rs1524107 & 0.05 & 0.18 & 0.29 & 0.27 & 1.31 & 0.25 & 0.22 & 0.22 & 0.64 \\
\hline ApoE112 & $\mathrm{T} \rightarrow \mathrm{C}$ & Exon & rs429358 & $0.15^{*}$ & 0.01 & 0.00 & 0.08 & 0.17 & 0.68 & 0.23 & 1.24 & 0.27 \\
\hline ApoE158 & $C \rightarrow T$ & Exon & rs7412 & $0.08^{*}$ & 0.05 & 0.11 & 0.08 & 1.49 & 0.22 & 0.06 & 0.001 & 0.97 \\
\hline
\end{tabular}

Abbreviations: CEU, Utah residents with Northern and Western European ancestry from the CEPH collection; JPT, Japanese in Tokyo, Japan; CHB, Han Chinese in Beijing; HWE $p, p$ value for Hardy-Weinberg equilibrium test; MAF, minor allele frequency; SNP, single nucleotide polymorphism.

The degree of freedom is 1 for all HWE tests.

* MAF data were obtained from dbSNP because the data was not available from the HapMap Project. 
Table 4 Association between IL-6 SNPs and LOAD risk by ApoE e4 status

\begin{tabular}{|c|c|c|c|c|c|c|c|}
\hline \multicolumn{6}{|c|}{ Dominant model } & \multicolumn{2}{|c|}{ Additive model } \\
\hline & \multicolumn{2}{|c|}{0 copies } & \multicolumn{3}{|c|}{1 or 2 copies } & \multirow[b]{2}{*}{ AOR $(95 \% \mathrm{Cl})$} & \multirow[b]{2}{*}{$p$} \\
\hline & $\begin{array}{l}\text { Case/ } \\
\text { control }\end{array}$ & AOR & $\begin{array}{l}\text { Case/ } \\
\text { control }\end{array}$ & AOR $(95 \% \mathrm{Cl})$ & $p$ & & \\
\hline SNP1 & $162 / 245$ & 1.00 & $104 / 196$ & $0.64(0.43-0.94)^{*}$ & 0.02 & $0.67(0.50-0.91)^{*}$ & 0.01 \\
\hline ApoE e4 non-carriers & $100 / 207$ & 1.00 & $61 / 166$ & $0.56(0.35-0.90)^{*}$ & 0.02 & $0.61(0.42-0.90)^{*}$ & 0.01 \\
\hline ApoE e4 carriers & $61 / 37$ & 1.00 & $43 / 29$ & $0.82(0.40-1.70)$ & 0.60 & $0.81(0.49-1.34)$ & 0.28 \\
\hline SNP2 & $180 / 293$ & 1.00 & $75 / 141$ & $0.78(0.51-1.19)$ & 0.25 & $0.80(0.56-1.14)$ & 0.21 \\
\hline ApoE e4 non-carriers & $114 / 249$ & 1.00 & $40 / 118$ & $0.72(0.43-1.20)$ & 0.21 & $0.72(0.46-1.12)$ & 0.14 \\
\hline ApoE e4 carriers & $66 / 43$ & 1.00 & $35 / 22$ & $0.89(0.42-1.91)$ & 0.77 & $0.99(0.54-1.83)$ & 0.59 \\
\hline SNP3 & $163 / 242$ & 1.00 & $102 / 199$ & $0.60(0.41-0.89)^{*}$ & 0.01 & $0.66(0.49-0.90)^{*}$ & $<0.01$ \\
\hline ApoE e4 non-carriers & $101 / 204$ & 1.00 & $60 / 169$ & $0.55(0.35-0.88)^{*}$ & 0.01 & $0.60(0.41-0.89)^{*}$ & 0.01 \\
\hline ApoE e4 carriers & $61 / 37$ & 1.00 & $42 / 29$ & $0.73(0.36-1.52)$ & 0.40 & $0.81(0.48-1.34)$ & 0.23 \\
\hline
\end{tabular}

All models were adjusted for age, gender, education, and $A p o E$ e4 status.

Abbreviations: AOR, adjusted odds ratio; LOAD, late-onset Alzheimer's disease; SNP, single nucleotide polymorphism.

* $p$ value remained significant after controlling for type I error by using FDR.

patients carrying 0 or 1 copy of HAP1 had a decreased risk of LOAD (AOR $=0.52,95 \% \mathrm{CI}=0.29-0.95$, Table 7). After stratification by type $2 \mathrm{DM}$, non-DM patients carrying minor HAP1 were associated with a decreased LOAD risk $(\mathrm{AOR}=0.59,95 \% \mathrm{CI}=0.39-0.92$, Table 7).

\section{Discussion}

In addition to replicating findings for rs 1800796 explored in previous Asian studies [12-14], this study

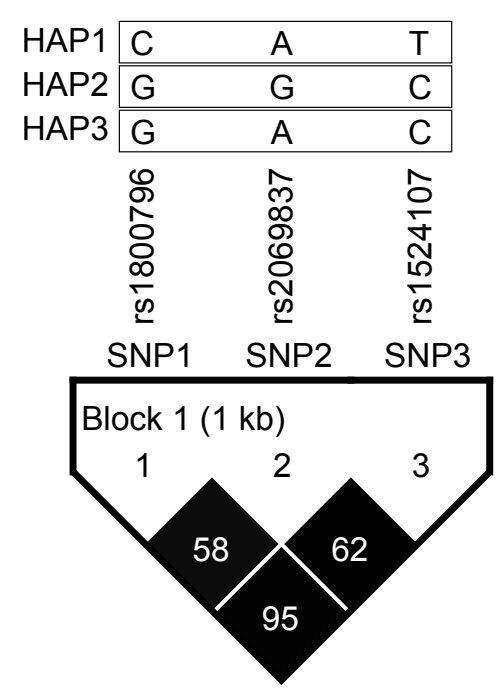

Figure 1 IL-6 linkage disequilibrium (LD) plot. This plot was generated by using a Haploview program. Three SNPs form one block. The SNP name, e.g., SNP1, SNP2, and SNP3; indicates the three htSNPs genotyped in this study. Three common haplotypes (frequency $\geq 0.05$ ) were identified. The level of pair wise $r^{2}$, which indicates the association degree between two SNPs in LD block, is shown numerically in the cell of the LD structure. The level of pairwise $D^{\prime}$, which indicates the strength of LD between two SNPs, is shown in the LD structure in gray scale. for the first time identifies two IL-6 htSNPs (rs2069837 and rs1524107) representative for the Chinese population, and rs1524107 showed a significant association with LOAD. We found that a variant of SNP rs1800796 is significantly associated with decreased risk of LOAD, which is consistent with the findings from a Chinese study [12]. In addition, we found that the intronic SNP rs1524107 and a haplotype CAT have a significant protective effect on LOAD risk, which has not been reported previously. Unlike rs1800796 and rs1524107, variant rs2068937 was not significantly associated with LOAD (Table 4). Although they are located in one block [i.e., highly linkage disequilibrium (LD) with dark gray in Figure 1], rs2068937 shows a low correlation with $\mathrm{rs} 1800796\left(\mathrm{r}^{2}=0.58\right)$ and $\mathrm{rs} 1524107\left(\mathrm{r}^{2}=0.62\right)$ which explains its lack of a significant association with LOAD.

rs1800796 is a promoter SNP, which may enhance transcription efficiency [28] and affect plasma CRP levels [29] and subsequent inflammatory responses. These results indicate that the promoter SNP rs1800796 might be involved in the course of inflammation, and the variant rs 1800796 could alter IL-6 production in the development of AD. Sequence variants of rs1524107 may affect disease risk via their effect on alternative splicing, e.g., altering mRNA folding or the stability of mRNA structure, and subsequent protein production. Besides, the most common IL- 6 haplotype CAT, composed of three major alleles, was associated with decreased risk of LOAD. Therefore, carrying 0 or 1 copies of CAT showed consistent protective effects on LOAD risk, as did the variant $I L-6$ SNPs. These sequence changes may either block or attenuate inflammation signaling which leads to reduced risk of AD. This supports the finding of a protective effect from $I L$ - 
Table 5 Association between IL-6 haplotypes and LOAD

\begin{tabular}{|c|c|c|c|c|c|c|}
\hline & \multirow[t]{2}{*}{ Prevalence in controls, $\%$} & \multicolumn{2}{|c|}{2 copies } & \multicolumn{3}{|c|}{1 or 0 copies } \\
\hline & & Case/Control & AOR & Case/Control & AOR $(95 \% \mathrm{Cl})$ & $p$ \\
\hline HAP1 $\left(\right.$ CAT) ${ }^{a}$ & 73.3 & $159 / 244$ & 1.00 & $107 / 200$ & $0.65(0.44-0.95)$ & 0.02 \\
\hline ApoE e4 non-carriers & & 99/206 & 1.00 & $62 / 170$ & $0.57(0.36-0.91)$ & 0.02 \\
\hline \multirow[t]{3}{*}{ ApoE e4 carriers } & & $59 / 37$ & 1.00 & $45 / 29$ & $0.85(0.42-1.76)$ & 0.67 \\
\hline & Prevalence in controls, \% & \multicolumn{2}{|c|}{0 copies } & \multicolumn{3}{|c|}{1 or 2 copies } \\
\hline & & Case/Control & AOR & Case/Control & AOR $(95 \% \mathrm{Cl})$ & p \\
\hline HAP2 (GGC) & 17.8 & $263 / 439$ & 1.00 & $3 / 5$ & $1.10(0.16-7.58)$ & 0.92 \\
\hline HAP3 (GAC) & 8.1 & $260 / 442$ & 1.00 & $6 / 2$ & $2.56(0.39-16.95)$ & 0.33 \\
\hline
\end{tabular}

a Two copies of HAP1 was used as the reference group because it is a "major" haplotype (haplotype frequency $>0.5$ ). Abbreviations: AOR, adjusted odds ratio; HAP, haplotype; LOAD, late-onset Alzheimer's disease.

All models were adjusted for age, gender, education, and ApOE e4 status.

6 polymorphisms on LOAD. The postulated mechanism of IL-6 in LOAD is demonstrated in Figure 2.

Although ApoE e4 status is a well-known predictor for $\mathrm{AD}$ risk, over half of $\mathrm{AD}$ cases $(61 \%$ in this study, Table 2) do not carry the ApoE e4 allele. Therefore, prediction of LOAD risk among ApoE e4 non-carriers becomes an important task. This study found significant associations

Table 6 Association between IL-6 SNPs and LOAD by hypertension or type 2 DM

\begin{tabular}{|c|c|c|c|c|c|}
\hline \multicolumn{5}{|c|}{ Dominant model } & \multirow[t]{3}{*}{$p_{\text {interaction }}$} \\
\hline & \multicolumn{2}{|c|}{0 copies } & \multicolumn{2}{|c|}{1 or 2 copies } & \\
\hline & $\begin{array}{l}\text { Case/ } \\
\text { Control }\end{array}$ & AOR & $\begin{array}{l}\text { Case/ } \\
\text { Control }\end{array}$ & AOR (95\% CI) & \\
\hline Hypertension & $266 / 443$ & & & $0.41(0.28-0.60)$ & NA \\
\hline \multicolumn{6}{|c|}{ SNP1 } \\
\hline No & $96 / 105$ & 1.00 & $69 / 98$ & $0.64(0.37-1.09)$ & 0.54 \\
\hline Yes & $66 / 139$ & 1.00 & $35 / 98$ & $0.53(0.29-0.96)^{*}$ & \\
\hline \multicolumn{6}{|l|}{ SNP2 } \\
\hline No & $106 / 131$ & 1.00 & $52 / 67$ & $1.09(0.61-1.92)$ & 0.03 \\
\hline Yes & $74 / 161$ & 1.00 & $23 / 74$ & $0.43(0.22-0.86)^{*}$ & \\
\hline \multicolumn{6}{|l|}{ SNP3 } \\
\hline No & $99 / 102$ & 1.00 & $66 / 100$ & $0.59(0.34-1.01)$ & 0.74 \\
\hline Yes & $64 / 139$ & 1.00 & $36 / 99$ & $0.53(0.29-0.97)^{*}$ & \\
\hline Type 2 DM & $263 / 442$ & & & $0.47(0.30-0.74)$ & NA \\
\hline \multicolumn{6}{|l|}{ SNP1 } \\
\hline No & $136 / 210$ & 1.00 & $81 / 167$ & $0.58(0.38-0.90)^{*}$ & 0.48 \\
\hline Yes & $25 / 33$ & 1.00 & $23 / 29$ & $0.91(0.36-1.31)$ & \\
\hline \multicolumn{6}{|l|}{ SNP2 } \\
\hline No & $146 / 251$ & 1.00 & $61 / 119$ & $0.77(0.48-1.23)$ & 0.96 \\
\hline Yes & $33 / 40$ & 1.00 & $14 / 22$ & $0.78(0.28-2.20)$ & \\
\hline \multicolumn{6}{|l|}{ SNP3 } \\
\hline No & $136 / 207$ & 1.00 & $80 / 171$ & $0.54(0.35-0.84)^{*}$ & 0.39 \\
\hline Yes & $26 / 33$ & 1.00 & $22 / 28$ & $0.92(0.37-2.31)$ & \\
\hline
\end{tabular}

${ }^{a} p_{\text {interaction }}$ value was obtained by using the dominant model. All models were adjusted for age, gender, education, and $A p o E$ e4 status. Abbreviations: AOR, adjusted odds ratio; DM, diabetes mellitus; LOAD, lateonset Alzheimer's disease; SNP, single nucleotide polymorphism; NA, not applicable.

* Result remained significant after controlling for type I error by using FDR between rs1800796 or rs1524107 and LOAD in ApoE e4 non-carriers, which remained statistically significant after correction for type I error by using FDR. A Chinese study [13] found that the variant rs 1800796 was associated with $\mathrm{AD}$ risk in $A p o E$ e4 carriers but not in the wider population. This may be a chance finding because a significant protective effect of rs1800796 variants on AD risk was observed only after stratification by ApoE e4 status. In contrast, both $\mathrm{He}$ et al. [12] and our study found a significant association before stratification. A previous study showed that elevated serum IL6 induces hypertriglyceridemia [30], which manifests before the deposition of beta amyloid $(\mathrm{A} \beta)$ in $\mathrm{AD}$ [31]. Therefore, $I L-6$ polymorphisms may be important in predicting LOAD in ApoE e4 non-carriers.

Genotyping data from public domains (HapMap and dbSNP) show that $I L-6$ and ApoE SNPs show geographic variations (Table 3). MAFs of three IL-6 SNPs (rs1800796, rs2069837, and rs1524107) are similar for

Table 7 Association between IL-6 haplotype CAT and LOAD by hypertension or type $2 \mathrm{DM}$

\begin{tabular}{|c|c|c|c|c|c|}
\hline & \multicolumn{2}{|c|}{2 copies $^{a}$} & \multicolumn{2}{|c|}{0 or 1 copy } & \multirow[t]{2}{*}{$p_{\text {interaction }}{ }^{\mathrm{b}}$} \\
\hline & $\begin{array}{l}\text { Case/ } \\
\text { Control }\end{array}$ & AOR & $\begin{array}{l}\text { Case/ } \\
\text { Control }\end{array}$ & $\begin{array}{c}\text { AOR } \\
(95 \% \mathrm{Cl})\end{array}$ & \\
\hline \multicolumn{6}{|c|}{ Hypertension } \\
\hline No & $94 / 104$ & 1.00 & $71 / 100$ & $\begin{array}{c}0.67 \\
(0.39-1.15)\end{array}$ & 0.49 \\
\hline Yes & $65 / 139$ & 1.00 & $36 / 100$ & $\begin{array}{c}0.52 \\
(0.29-0.95)\end{array}$ & \\
\hline \multicolumn{6}{|c|}{ Type 2 DM } \\
\hline No & $133 / 209$ & 1.00 & $84 / 171$ & $\begin{array}{c}0.59 \\
(0.39-0.92)\end{array}$ & 0.36 \\
\hline Yes & $25 / 33$ & 1.00 & $23 / 29$ & $\begin{array}{c}0.91 \\
(0.36-2.26)\end{array}$ & \\
\hline
\end{tabular}

Abbreviation: AOR, adjusted odds ratio; DM, diabetes mellitus; LOAD, lateonset Alzheimer's disease.

All models were adjusted for age, gender, education, and $A p O E$ e4 status.

a 2 copies of haplotype CAT was used as the reference group because it is a major haplotype.

${ }^{\mathrm{b}} p_{\text {interaction }}$ value was obtained by using the dominant model. 


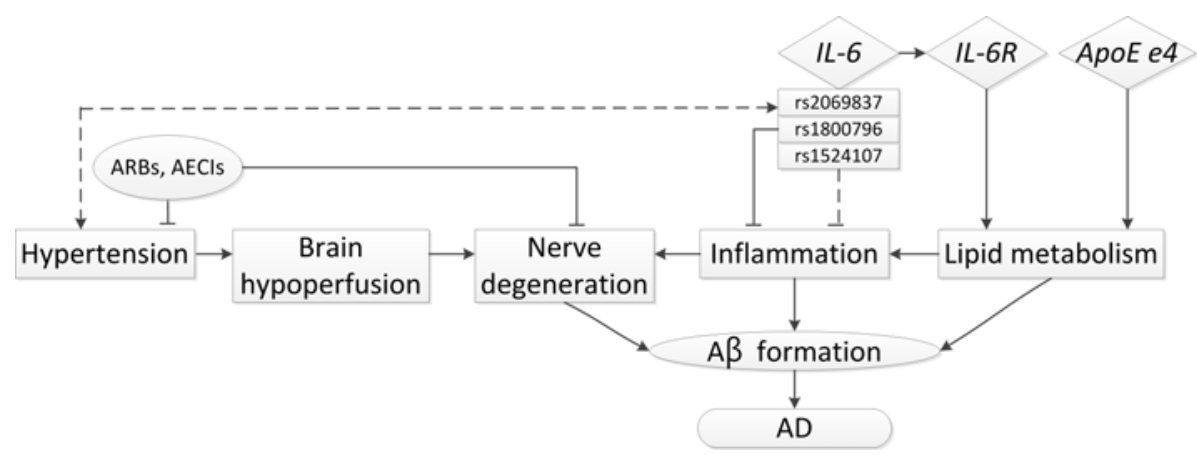

Figure 2 Postulated pathway of IL- 6 and factors involved in the pathogenesis of dementia. Solid lines indicate pathways that have been well documented; dotted lines indicated speculative pathways. Abbreviations: A $\beta$, beta amyloid; IL-6R, interleukin 6 receptor; ARBs, angiotensin receptor blockers; $\mathrm{AECls}$, angiotensin-converting enzyme inhibitors; $A p o E$ e4, apolipoprotein E e4; $A D$, Alzheimer's disease.

controls of this Chinese population (0.19-0.27) and CHB of the HapMap project (0.17-0.29). In comparison with these two Chinese populations, for the same IL-6 SNPs, Japanese populations have lower MAFs (0.10-0.18), and the MAFs are even lower in Caucasians (0.04-0.08). For ApoE SNPs, the MAF of AopE112 (rs429358) is highest among Caucasians (dbSNP: 0.15), followed by controls in this Chinese population (0.08), and by Japanese (0.01) and CHB (0.00) from the HapMap Project. The inconsistency between the two Chinese populations for ApoE112 may be attributable to the small number of samples genotyped in HapMap study ( $\mathrm{n}=45$ for $\mathrm{CHB}$ and $\mathrm{n}=43$ for JPN). For ApoE158 (rs7412), the MAFs were similar between Chinese (0.08-0.11) and Caucasians (0.08) across ethnic groups with a lower value observed in Japanese (0.05).

Hypertension significantly modified the association of IL-6 SNPs with LOAD risk. The protective effect of three IL-6 SNPs for LOAD was especially evident among participants with hypertension (Table 6), which may be a result of medication for treating hypertension that can lower inflammatory responses (Figure 2). For example, angiotensin receptor blockers or angiotensinconverting enzyme inhibitors have been used to lower blood pressure. Their accompanying neuroprotective effects can reduce neuronal damage and lead to slowed progression of AD $[32,33]$. Sequence variants of $I L-6$ may lower blood pressure, and subsequent brain hypoperfusion and neural degeneration, which eventually decreases LOAD risk (Figure 2). However, experimental studies are needed to clarify the underlying mechanism.

This study had some strengths. First, the htSNPs in $I L-6$ were identified to explore LOAD risk for the first time. Second, the selection of two representative htSNPs captured abundant genetic information regarding the $I L-6$ gene $\left(r^{2}=1.00\right)$ as compared to the genetic information captured by the single promoter SNP (rs1800796, $\mathrm{r}^{2}=$ $0.81)$ in previous candidate-gene studies $[12,13]$. Third, the associations between $I L-6$ SNPs and LOAD risk remained significant after correction for type I error using FDR, which indicates that these findings are not chance findings. In addition, high false positive rate in genomewide association studies prevent identifying SNPs associated with disease outcome but with moderate $p$ values in the exploratory stage [34]. This study, which selected htSNPs that are representative for Chinese and captured abundant genetic information for $I L-6$, may solve the above issue. Furthermore, brain imaging was used to exclude other diseases with similar presentation as LOAD.

Our study had some limitations. A self-report questionnaire was used to collect information on vascular risk factors (e.g., hypertension, hyperlipidemia, and type 2 DM). Because these diseases/conditions are major health issues, participants' recall of disease/condition diagnosis and their awareness of these diseases/conditions tend to be relatively accurate [35-37]. Therefore, information bias should not be a concern.

\section{Conclusions}

In addition to a significant association of rs1800796 with LOAD, this study for the first time found that an $I L-6$ htSNP (rs1524107) and a haplotype CAT were significantly associated with LOAD risk after correction for multiple tests. These associations remained significant in ApoE e4 non-carriers only. Because the majority of AD patients are $A p o E$ e 4 non-carriers (61\% in this study and another Chinese study [13]), IL-6 SNPs may be important markers in predicting LOAD risk in ApoE e4 noncarriers. In addition, hypertension significantly modified the association of $I L-6$ polymorphisms with LOAD risk. Future large studies are warranted to explore the role of IL-6 in risk of LOAD.

\section{Abbreviations}

$A \beta$ : Beta amyloid; AD: Alzheimer's disease; AOR: Adjusted odds ratio; ApoE: Apolipoprotein; CHB: Han Chinese in Beijing China; Cl: Confidence interval; 
CRP: C-reactive protein; DM: Diabetes mellitus; FDR: False discovery rate; HAP: Haplotype; htSNPs: Haplotype-tagging SNPs; HWE: Hardy-Weinberg equilibrium; LD: Linkage disequilibrium; LOAD: Late-onset Alzheimer's disease; MAF: Minor allele frequency; SNP: Single nucleotide polymorphism.

\section{Acknowledgements}

Grant support: NSC 96-2314-B-002-197 and NSC 97-2314-B-002-168-MY3.

\begin{abstract}
Author details
'Institute of Epidemiology and Preventive Medicine, College of Public Health, National Taiwan University, Taipei, Taiwan. ${ }^{2}$ Department of Neurology, National Taiwan University Hospital, Taipei, Taiwan. ${ }^{3}$ Graduate Institute of Physiology, College of Medicine, National Taiwan University, Taipei, Taiwan. ${ }^{4}$ Department of Geriatrics and Gerontology, National Taiwan University Hospital, Taipei, Taiwan. ${ }^{5}$ Department of Neurology, En Chu Kong Hospital, Taipei, Taiwan. ${ }^{6}$ Center of Laboratory Medicine, En Chu Kong Hospital, Taipei, Taiwan. ${ }^{7}$ Center of Neurological Medicine, Cardinal Tien Hospital,Taipei, Taiwan. ${ }^{8}$ Department of Laboratory Medicine, Cardinal Tien Hospital,Taipei, Taiwan. ${ }^{9}$ Department of Medicine, School of Medicine, Fu-Jen Catholic University, Taipei, Taiwan. ${ }^{10}$ Department of Public Health, National Taiwan University, Taipei, Taiwan. ${ }^{11}$ Research Center for Genes, Environment and Human Health, College of Public Health, National Taiwan University, Taipei, Taiwan.
\end{abstract}

\section{Authors' contributions}

SYC: data analysis and manuscript writing; TFC: participant recruitment; LCL: technical review; JHC: participant recruitment and study design; YS: participant recruitment; LLW: biospecimen collection and treatment; PKY: participant recruitment; YMC: biospecimen collection and treatment; YCC: conceive of this study, genetic data analyses, manuscript writing. All authors of this research paper have directly participated in the planning, execution, or analysis of the study. All authors of this paper have read and approved the final version submitted.

\section{Competing interests}

The authors declare that they have no competing interests.

Received: 29 October 2011 Accepted: 24 January 2012

Published: 24 January 2012

\section{References}

1. Alzheimer's Association: 2010 Alzheimer's Disease Facts and Figures. Alzheimer's \& Dementia.[http://www.alz.org/ alzheimers_disease_facts_figures.asp?type=homepage].

2. Fuh $\mathrm{JL}$, Wang SJ: Dementia in Taiwan: past, present, and future. Acta Neurol Taiwan 2008, 17:153-161.

3. Gadient RA, Otten UH: Interleukin-6 (IL-6)-a molecule with both beneficial and destructive potentials. Prog Neurobiol 1997, 52:379-390.

4. Heyser CJ, Masliah E, Samimi A, Campbell IL, Gold LH: Progressive decline in avoidance learning paralleled by inflammatory neurodegeneration in transgenic mice expressing interleukin 6 in the brain. Proc Natl Acad Sci USA 1997, 94:1500-1505.

5. Castell JV, Andus T, Kunz D, Heinrich PC: Interleukin-6: the major regulator of acute-phase protein synthesis in man and rat. Ann NY Acad Sci 1989, 557:87-99.

6. Quintanilla RA, Orellana DI, Gonzalez-Billáult C, Maccioni RB: Interleukin-6 induces Alzheimer-type phosphorylation of tau protein by deregulating the cdk5/p35 pathway. Exp Cell Res 2004, 295:245-257.

7. Querfurth HW, LaFerla FM: Alzheimer's disease. N Engl I Med 2010, 362:329-344.

8. Licastro F, Grimaldi LM, Bonafè M, Martina C, Olivieri F, Cavallone L, Giovanietti S, Masliah E, Franceschi C: Interleukin-6 gene alleles affect the risk of Alzheimer's disease and levels of the cytokine in blood and brain. Neurobiol Aging 2003, 24:921-926.

9. Arosio B, Trabattoni D, Galimberti L, Bucciarelli P, Fasano F, Calabresi C, Cazzullo CL, Vergani C, Annoni G, Clerici M: Interleukin-10 and interleukin6 gene polymorphisms as risk factors for Alzheimer's disease. Neurobiol Aging 2004, 25:1009-1015.

10. Depboylu C, Lohmüller F, Gocke P, Du Y, Zimmer R, Gasser T, Klockgether T, Dodel RC: An interleukin-6 promoter variant is not associated with an increased risk for Alzheimer's disease. Dement Geriatr Cogn Disord 2004, 17:170-173.

11. van Oijen M, Arp PP, de Jong FJ, Hofman A, Koudstaal PJ, Uitterlinden AG, Breteler MM: Polymorphisms in the interleukin 6 and transforming growth factor beta1 gene and risk of dementia. The Rotterdam study. Neurosci Lett 2006, 402:113-117.

12. He MX, Yang WL, Zhang MM, Lian YJ, Hua HY, Zeng JS, Zhang LR: Association between interleukin- 6 gene promoter-572 C/G polymorphism and the risk of sporadic Alzheimer's disease. Neurol Sci 2010, 31:165-168.

13. Wang M, Jia J: The interleukin-6 gene-572 C/G promoter polymorphism modifies Alzheimer's risk in ApoE epsilon 4 carriers. Neurosci Lett 2010, 482:260-263.

14. Nishimura M, Sakamoto T, Kaji R, Kawakami H: Influence of polymorphisms in the genes for cytokines and glutathione S-transferase omega on sporadic Alzheimer's disease. Neurosci Lett 2004, 368:140-143.

15. Lim CS, Zheng S, Kim YS, Ahn C, Han JS, Kim S, Lee JS, Chae DW: The -174 $\mathrm{G}$ to $\mathrm{C}$ polymorphism of interleukin- 6 gene is very rare in Koreans. Cytokine 2002, 19:52-54.

16. Fillit $H$, Nash DT, Rundek T, Zuckerman A: Cardiovascular risk factors and dementia. Am J Geriatr Pharmacother 2008, 6:100-118.

17. Román GC: Vascular dementia prevention: a risk factor analysis. Cerebrovasc Dis 2005, 20(Suppl 2):91-100.

18. Stozická Z, Zilka N, Novák M: Risk and protective factors for sporadic Alzheimer's disease. Acta Virol 2007, 51:205-222.

19. American Psychiatric Association: Diagnostic and statistical manual of mental disorders. Washington, DC , 41994.

20. McKhann G, Drachman D, Folstein M, Katzman R, Price D, Stadlan EM: Clinical diagnosis of Alzheimer's disease: report of the NINCDS-ADRDA Work Group under the auspices of Department of Health and Human Services Task Force on Alzheimer's Disease. Neurology 1984, 34:939-944.

21. Pfeiffer E: A short portable mental status questionnaire for the assessment of organic brain deficit in elderly patients. J Am Geriatr Soc 1975, 23:433-441.

22. Chen YC, Giovannucci E, Lazarus R, Kraft P, Ketkar S, Hunter DJ: Sequence variants of Toll-like receptor 4 and susceptibility to prostate cancer. Cancer Res 2005, 65:11771-11778.

23. Gabriel SB, Schaffner SF, Nguyen H, Moore JM, Roy J, Blumenstiel B, Higgins J, DeFelice M, Lochner A, Faggart M, Liu-Cordero SN, Rotimi C, Adeyemo A, Cooper R, Ward R, Lander ES, Daly MJ, Altshuler D: The structure of haplotype blocks in the human genome. Science 2002, 296:2225-2229.

24. Stram DO, Leigh Pearce C, Bretsky P, Freedman M, Hirschhorn JN, Altshuler D, Kolonel LN, Henderson BE, Thomas DC: Modeling and E-M estimation of haplotype-specific relative risks from genotype data for a case-control study of unrelated individuals. Hum Hered 2003, 55:179-190.

25. Chapman J, Estupiñan J, Asherov A, Goldfarb LG: A simple and efficient method for apolipoprotein E genotype determination. Neurology 1996, 46:1484-1485.

26. Ghebranious N, Ivacic L, Mallum J, Dokken C: Detection of ApoE E2, E3 and E4 alleles using MALDI-TOF mass spectrometry and the homogeneous mass-extend technology. Nucleic Acids Res 2005, 33(17): e149.

27. Benjamini $Y$, Hochberg $Y$ : Controlling the false discovery rate: a practical and powerful approach to multiple testing. J R Statist Soc B 1995, 57:289-300.

28. Brull DJ, Montgomery HE, Sanders J, Dhamrait S, Luong L, Rumley A, Lowe GD, Humphries SE: Interleukin-6 gene $-174 \mathrm{~g}>\mathrm{c}$ and $-572 \mathrm{~g}>\mathrm{c}$ promoter polymorphisms are strong predictors of plasma interleukin-6 levels after coronary artery bypass surgery. Arterioscler Thromb Vasc Biol 2001, 21:1458-1463.

29. Wong LY, Leung RY, Ong KL, Cheung BM: Plasma levels of fibrinogen and C-reactive protein are related to interleukin- 6 gene -572 C > G polymorphism in subjects with and without hypertension. J Hum Hypertens 2007, 21:875-882.

30. Nonogaki K, Iguchi A: Stress, acute hyperglycemia, and hyperlipidemia role of the autonomic nervous system and cytokines. Trends Endocrinol Metab 1997, 8:192-197.

31. Burgess BL, Mclsaac SA, Naus KE, Chan JY, Tansley GH, Yang J, Miao F, Ross CJ, van Eck M, Hayden MR, van Nostrand W, St George-Hyslop P, Westaway $D$, Wellington $C L$ : Elevated plasma triglyceride levels precede 
amyloid deposition in Alzheimer's disease mouse models with abundant A beta in plasma. Neurobiol Dis 2006, 24:114-127.

32. Hajjar IM, Keown M, Lewis $P$, Almor A: Angiotensin converting enzyme inhibitors and cognitive and functional decline in patients with Alzheimer's disease: an observational study. Am J Alzheimers Dis Other Demen 2008, 23:77-83.

33. Li NC, Lee A, Whitmer RA, Kivipelto M, Lawler E, Kazis LE, Wolozin B: Use of angiotensin receptor blockers and risk of dementia in a predominantly male population: prospective cohort analysis. BMJ 2010, 12:b5465.

34. Zheng SL, Liu W, Wiklund F, Dimitrov L, Bälter K, Sun J, Adami HO, Johansson JE, Sun J, Chang B, Loza M, Turner AR, Bleecker ER, Meyers DA, Carpten JD, Duggan D, Isaacs WB, Xu J, Grönberg H: A comprehensive association study for genes in inflammation pathway provides support for their roles in prostate cancer risk in the CAPS study. Prostate 2006, 66(14):1556-1564.

35. El Fakiri F, Bruijnzeels MA, Hoes AW: No evidence for marked ethnic differences in accuracy of self-reported diabetes, hypertension, and hypercholesterolemia. J Clin Epidemiol 2007, 60:1271-1279.

36. Okura Y, Urban LH, Mahoney DW, Jacobsen SJ, Rodehceffer RJ: Agreement between self-report questionnaires and medical record data was substantial for diabetes, hypertension, myocardial infarction and stroke but not for heart failure. J Clin Epidemiol 2004, 57:1096-1103.

37. St Sauver JL, Hagen PT, Cha SS, Bagniewski SM, Mandrekar JN, Curoe AM, Rodeheffer RJ, Roger VL, Jacobsen SJ: Agreement between patient reports of cardiovascular disease and patient medical records. Mayo Clin Proc 2005, 80:203-210.

doi:10.1186/1742-2094-9-21

Cite this article as: Chen et al:: Sequence variants of interleukin 6 (IL-6) are significantly associated with a decreased risk of late-onset Alzheimer's disease. Journal of Neuroinflammation 2012 9:21.

\section{Submit your next manuscript to BioMed Central and take full advantage of:}

- Convenient online submission

- Thorough peer review

- No space constraints or color figure charges

- Immediate publication on acceptance

- Inclusion in PubMed, CAS, Scopus and Google Scholar

- Research which is freely available for redistribution

Submit your manuscript at www.biomedcentral.com/submit
Biomed Central 